\title{
DIAGNÓSTICO DOS CRIMES CONTRA A FLORA A PARTIR DAS AÇÕES IMPETRADAS PELO MINISTÉRIO PÚBLICO FEDERAL
}

\section{DIAGNOSIS OF CRIMES AGAINST THE FLORA FROM LAWSUITS FILED BY FEDERAL PROSECUTORS}

\begin{abstract}
ANNe Michelle TAVARES FonseCA
Possui graduação em Engenharia Florestal pela Universidade Federal do Amazonas.

Luciana MONTENEgro VALENTE

Possui graduação em Direito pela Universidade Federal do Amazonas (1997) e mestrado em Direito Ambiental - Pace University (2002). Atualmente é analista processual - Procuradoria da República no Amazonas.

MARCILEIA COUTEIRO LOPES

Professora de Carreira da Universidade Federal do Amazonas. Chefe do Departamento de Ciências Florestais. Participa do Comitê de Extensão da UFAM.
\end{abstract}

\begin{abstract}
RESUMO
O aumento da degradação e a pressão pelo desmatamento na Amazônia evidenciam a necessidade de ações eficazes quanto às atividades lesivas ocasionadas pelo ser humano. Este estudo teve como objetivo diagnosticar e analisar os crimes contra a flora no Amazonas a partir das ações impetradas pelo Ministério Público Federal no período de 2009 a 2010. A metodologia utilizada teve como base a coleta de dados (na Justiça Federal e no MPF do Amazonas), tabulação das informações e análise qualiquantitativa. O desmatamento ilegal foi o crime contra a flora com maior ocorrência no Estado, durante o período estudado, sendo cometido com maior frequência nos municípios de Lábrea, Manaus e Boca do Acre. No sul do Amazonas, os crimes são ocasionados por pessoas vindas de outro estado, sendo que alguns destes infratores já respondem a outros processos ambientais em fóruns de outro estado brasileiro.
\end{abstract}

Palavras-chave: Amazonas; Crimes Ambientais; Justiça Federal; Recursos Florestais.

\begin{abstract}
Increased degradation and pressure for deforestation in the Amazon highlights the need for effective action regarding activities harmful caused by humans. This study aimed to diagnose and analyze crimes against flora in the Amazon from lawsuits filed by federal prosecutors in the period 2009-2010. The methodology was based on data collection (in Federal Court and in the Amazon MPF), tabulation of information and qualitative and quantitative analysis. Illegal deforestation was the crime against pathogens with higher occurrence in the state during the period studied, being committed more frequently in counties Lábrea, Manaus and Boca do Acre. In the south of the Amazon, the crimes are caused by people from another state, and that some of these offenders already respond to other environmental processes in forums other Brazilian state.
\end{abstract}

Keywords: Amazonas; Environmental Crimes; Federal Justice; Forest Resource. 


\section{SUMÁRIO}

INTRODUÇAO; 1 CRIMES CONTRA A FLORA COMETIDOS NO ESTADO DO AMAZONAS NO PERÍODO DE 2009 E 2010; 2 CARACTERÍSTICAS DOS PROCESSOS ANALISADOS; 2.1 Perfil dos infratores; 2.2 Tipologia dos crimes contra a flora; 2.3 Zoneamento das áreas de ocorrência dos crimes contra a flora; 2.4 Condições dos processos na justiça federal; 2.5 Relação dos Crimes Contra a Flora e as Perícias Realizadas; 2.6 Hipóteses indicadoras de crimes contra a flora, no estado do Amazonas; CONCLUSÃO; REFERÊNCIAS.

\section{INTRODUÇÃO}

Os ecossistemas florestais desenvolvem relevante papel no desenvolvimento de inúmeras espécies. Entretanto, são os que mais sofrem no processo de interação homem $x$ natureza ${ }^{1}$.

Neste processo de interação, estão os recursos da Flora. Com relação à Flora brasileira, está apresenta rica diversidade de espécies distribuídas entre os vários biomas brasileiros.

Porém flora e floresta não são expressões sinônimas. Flora é o "conjunto de espécies vegetais de uma determinada região ou período geológico”. Floresta é compreendida como a “formação florística de porte arbóreo, mesmo em formação"2.

A Floresta Amazônica, conhecida mundialmente pela sua diversidade biológica, vem sendo destruída pelo desmatamento resultante das atividades de exploração ilegal de madeira e expansão da agropecuária que colocam em risco espécies da fauna e flora.

No Amazonas, constata-se que as áreas mais críticas do desmatamento concentram-se, principalmente, ao longo das rodovias AM - 237, BR - 317 e BR - 230, nos municípios do sul do Estado e do Baixo Amazonas, onde a expansão da atividade pecuária e o estabelecimento de projetos de assentamento muito tem contribuído para a derrubada de florestas ${ }^{3}$.

\footnotetext{
${ }^{1}$ NETO, Nicolau Dino de Castro e Costa; FILHO, Ney de Barros Bello; COSTA, Flávio Dino de Castro e. Crimes e Infrações Administrativas Ambientais: comentários à Lei no 9.605/98, 2a edição rev. e atual. Brasília: Brasília Jurídica, 2001 a.

${ }^{2}$ NETO, Nicolau Dino de Castro e Costa; FILHO, Ney de Barros Bello; COSTA, Flávio Dino de Castro e. Crimes e Infrações Administrativas Ambientais: comentários à Lei no 9.605/98, 2a edição rev. e atual. Brasília: Brasília Jurídica, 2001 a.

${ }^{3}$ SDS. Secretaria de Estado do Meio Ambiente e Desenvolvimento Sustentável. In: __ _, Plano Estadual de Prevenção e Combate ao Desmatamento no Amazonas. Manaus, 2008. Disponível em: <http://www.fundoamazonia.gov.br/FundoAmazonia/export/sites/default/site_pt/Galerias/Arquivos/Pub licacoes/Plano_Estadual_do_Amazonas.pdf>. Acesso em: 12 mar. 2011.
} 
Mediante o aumento destas atividades degradadoras, faz-se necessária a aplicação dos mecanismos jurídicos existentes para proteger o meio ambiente, considerando a gravidade dos danos ambientais. Dentre estes mecanismos, destaca-se a Lei de Crimes Ambientais (Lei n ${ }^{\circ}$ 9.605 de 12 de fevereiro de 1998), que penaliza no âmbito criminal, administrativo e civil, quem de qualquer forma, concorrer para a prática de crimes ambientais.

Esta lei trata nos artigos de 38 a 53 os tipos penais relativos à flora, criados em decorrência da necessidade de tutelar mais eficazmente esse bem jurídico.

Um dos principais avanços desta Lei foi a reunião em um só instrumento legal, de várias determinações que antes eram previstas em legislação esparsa e de difícil aplicação. A lei também elevou condutas que eram consideradas contravenções à categoria de crimes, como exemplo cita-se os desmatamentos ilegais ${ }^{4}$.

Em relação aos crimes ambientais, a ação penal é de iniciativa do Ministério Público. Sendo de natureza incondicionada, independente de qualquer provocação. O Órgão do Ministério Público à vista do inquérito policial, ou de quaisquer outros elementos de informação, poderá oferecer denúncia, desde que apresente indícios suficientes de materialidade e autoria do crime ambiental.

Com base nessa premissa, o presente trabalho objetiva realizar um diagnóstico dos crimes ambientais contra a flora no Estado do Amazonas, a partir da coleta e análise das ocorrências processadas perante a Justiça Federal, no período de 2009 a 2010.

Para a realização deste trabalho, a coleta de dados iniciou na sede do Ministério Público Federal, onde foram pesquisadas no banco de dados, as comunicações de crimes ambientais feitas a este órgão no período de 01 de Janeiro de 2009 à 31 de Dezembro de 2010. A partir desta pesquisa, as informações coletadas foram filtradas e o relatório das comunicações de crimes contra a flora foi impresso para a seleção das ações impetradas pelo Ministério Público Federal.

Posteriormente, foram consultados os processos judiciais através do sítio do Tribunal Regional Federal da Primeira Região, para localização dos mesmos. Os processos estavam distribuídos entre a $2^{\mathrm{a}}$ Vara - Criminal, a $4^{\mathrm{a}}$ Vara - Criminal e a $7^{\mathrm{a}}$ Vara - Ambiental e Agrária do Poder Judiciário Federal.

\footnotetext{
${ }^{4}$ BRITO, Brenda; BARRETO, Paulo. Aplicação da Lei de Crimes Ambientais pela Justiça Federal no Setor Florestal do Pará. Revista de Direito Ambiental. São Paulo. n. 37, p.218-243, 2005 a.
} 
A coleta de dados foi feita somente nos autos dos processos disponíveis na sede da Justiça Federal, devido ao fato de alguns estarem arquivados ou terem sido remetidos à Justiça Estadual por incompetência, ou seja, os crimes cometidos não lesionaram bens, serviços ou interesses da União.

$\mathrm{Na}$ consulta foram anotadas informações como: ano da denúncia, local da prática do crime, informações sobre o infrator, tipo de crime contra a flora, condições do processo e órgão fiscalizador.

Concomitantemente à pesquisa documental, foi realizada a pesquisa bibliográfica sobre o assunto e a legislação ambiental relacionada que constituíram um objeto teórico de auxílio no entendimento do estudo, permitindo tratar as informações obtidas.

\section{CRIMES CONTRA A FLORA COMETIDOS NO ESTADO DO AMAZONAS NO PERÍODO DE 2009 E 2010.}

Durante a pesquisa foram identificadas 901 comunicações de crimes ambientais encaminhadas para o Ministério Público Federal ajuizar ação penal. Destas, 135 tratavam de crimes contra a flora.

Dentre estas 135 comunicações, 53 eram procedimentos administrativos encaminhados pelo IBAMA, 31 eram Inquéritos Policiais, que estavam sendo investigados pela Polícia Federal para apurar os eventuais fatos delituosos e 51 eram processos judiciais impetrados pelo Ministério Público Federal. Sendo que destes 51 processos, 41 tratavam de crimes com ação direta sobre a flora como desmatamento, queimada e exploração ilegal (Figura 1). 


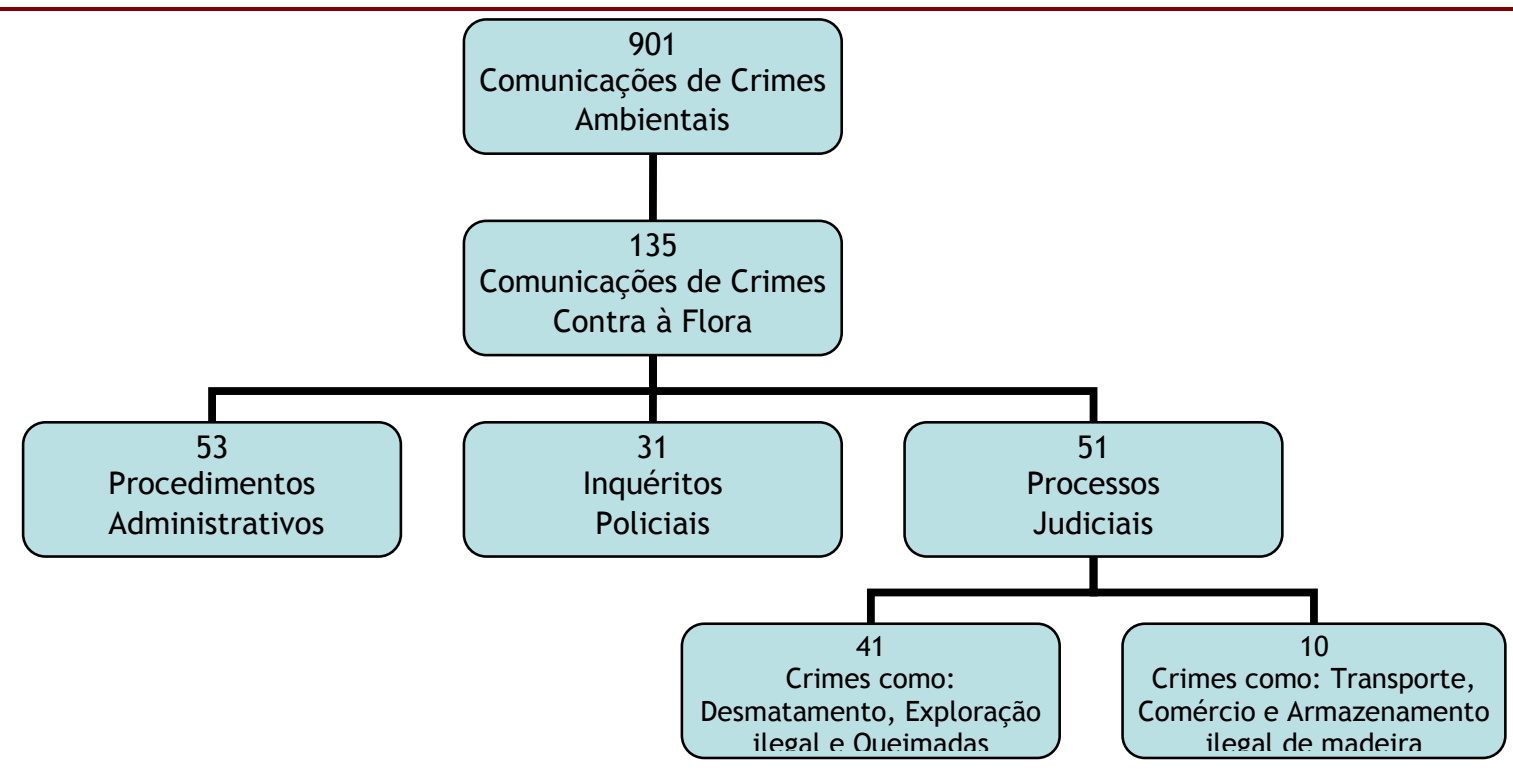

Figura 1: Quantificação dos crimes contra a flora no período de 2009 a 2010.

$\mathrm{Na}$ coleta de dados os crimes contra a flora como transporte, comercialização e armazenamento ilegal de madeira, não foram considerados por fazerem parte de outro estudo.

Foram analisados somente 28 processos judiciais que tramitavam na Justiça Federal no Estado do Amazonas, pois dos 41 processos, 10 estavam arquivados e 3 haviam sido encaminhados à Justiça Estadual.

Durante a análise dos processos, foi observado que apesar destas ações terem sido impetradas entre o período de 01 de Janeiro de 2009 a 31 de Dezembro de 2010, a maioria dos crimes contra a flora (32\%), ocorreu no ano de 2003 (Figura 2), ano em que ocorreu o maior índice de desmatamento no Amazonas, segundo as Ações de governo e mudanças climáticas da Secretaria de Estado do Meio Ambiente e Desenvolvimento Sustentável ${ }^{5}$. Apenas $7 \%$ dos crimes ocorreram no ano de 2009.

\begin{tabular}{|c|c|c|}
\hline Ano & $\begin{array}{c}\mathbf{N}^{\circ} \text { de Crimes } \\
\text { Contra a Flora }\end{array}$ & $\begin{array}{c}\% \text { de Crimes } \\
\text { Contra a Flora }\end{array}$ \\
\hline 2003 & 9 & $32 \%$ \\
\hline 2004 & 3 & $11 \%$ \\
\hline 2005 & 2 & $7 \%$ \\
\hline
\end{tabular}

\footnotetext{
${ }^{5}$ SDS. Secretaria de Estado do Meio Ambiente e Desenvolvimento Sustentável. In: __ _ Ações de governo e mudanças climáticas. Manaus, 2009. Disponível em: <http://www.senado.gov.br/sf/comissoes/CMMC/AP/AP20091119_CECLIMA.pdf>. Acesso em: 20 maio 2011.
} 


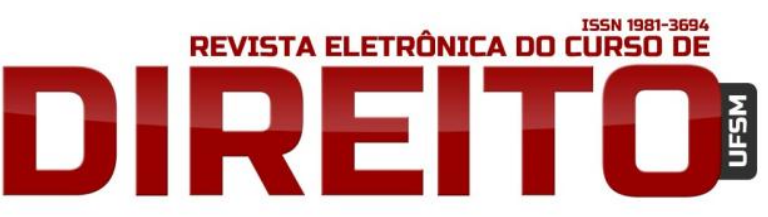

\begin{tabular}{|c|c|c|}
\hline $\mathbf{2 0 0 6}$ & 5 & $18 \%$ \\
\hline $\mathbf{2 0 0 7}$ & 6 & $21 \%$ \\
\hline 2008 & 1 & $4 \%$ \\
\hline 2009 & 2 & $7 \%$ \\
\hline
\end{tabular}

Figura 2: Ocorrência de crimes contra a flora por ano.

$\mathrm{Na}$ análise dos processos, observou-se que o ano de 2003 apresentou 8 crimes de desmatamento e 1 crime de queimada. 0 ano de 2007 foi o único ano que houve ocorrência dos três tipos de crime e no ano de 2009, assim como na maioria dos anos, o crime de desmatamento foi o crime que ocorreu em sua totalidade (Figura 3).

\begin{tabular}{|c|c|c|c|}
\hline \multirow{2}{*}{ Ano } & \multicolumn{3}{|c|}{ Tipo de Crime Contra a Flora } \\
\cline { 2 - 4 } & Desmatamento & Exploração & Queimada \\
\hline 2003 & 8 & & 1 \\
\hline 2004 & 3 & & \\
\hline 2005 & 2 & & \\
\hline 2006 & 3 & 2 & 1 \\
\hline 2007 & 3 & 2 & \\
\hline 2008 & 1 & & \\
\hline 2009 & 2 & & \\
\hline
\end{tabular}

Figura 3: Número e tipos de crime contra a flora por ano de ocorrência.

Acredita-se que a demora em impetrar as ações penais, deve-se a diversos fatores tais como: tempo de comunicação do crime ao Ministério Público Federal, devido ao trâmite do processo administrativo no órgão ambiental fiscalizador; informações insuficientes para ajuizar ação penal; conflito de competência entre a esfera federal e a esfera estadual e tempo demandado para realização do Inquérito Policial.

Esses fatores acabam contribuindo para a demora na punição dos infratores, que desrespeitam as leis e causam danos à flora.

\section{CARACTERÍSTICAS DOS PROCESSOS ANALISADOS}

\subsection{Perfil dos infratores.}


A grande maioria dos infratores dos processos analisados residia nos municípios do Amazonas e $21,4 \%$ eram residentes do estado do Acre (Figura 4).

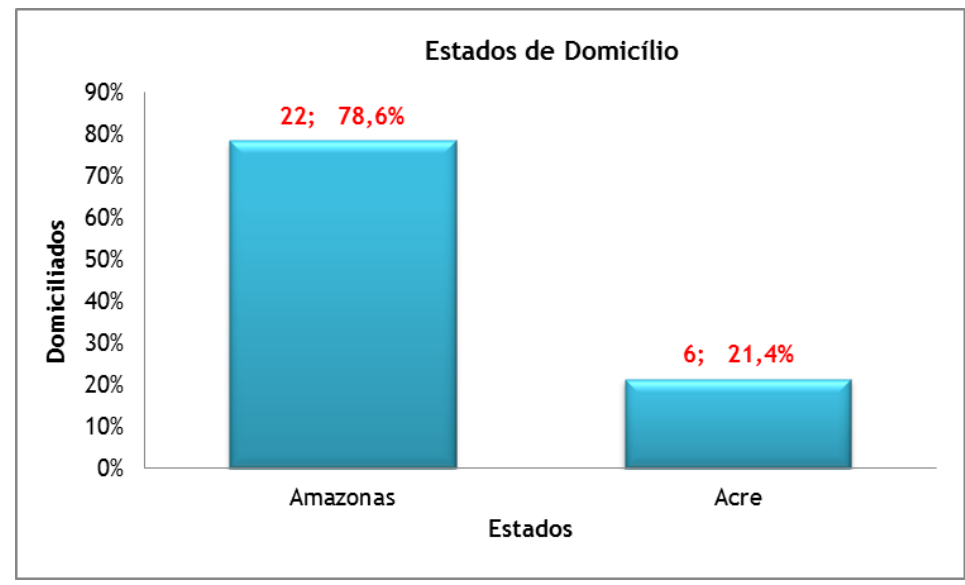

Figura 4: Número total e porcentagem dos infratores por estados de domicílio.

Este dado nos mostra que apesar de residirem no estado do Acre, as infrações eram cometidas em áreas do estado do Amazonas, principalmente nos municípios de fronteira entre os dois estados.

Do total de infratores residentes no Amazonas, $45 \%$ residiam em Manaus, $14 \%$ em Boca do Acre e Lábrea, 9\% em Barcelos e Novo Airão e 4,5\% residiam em Apuí e Guajará (Figura 5).

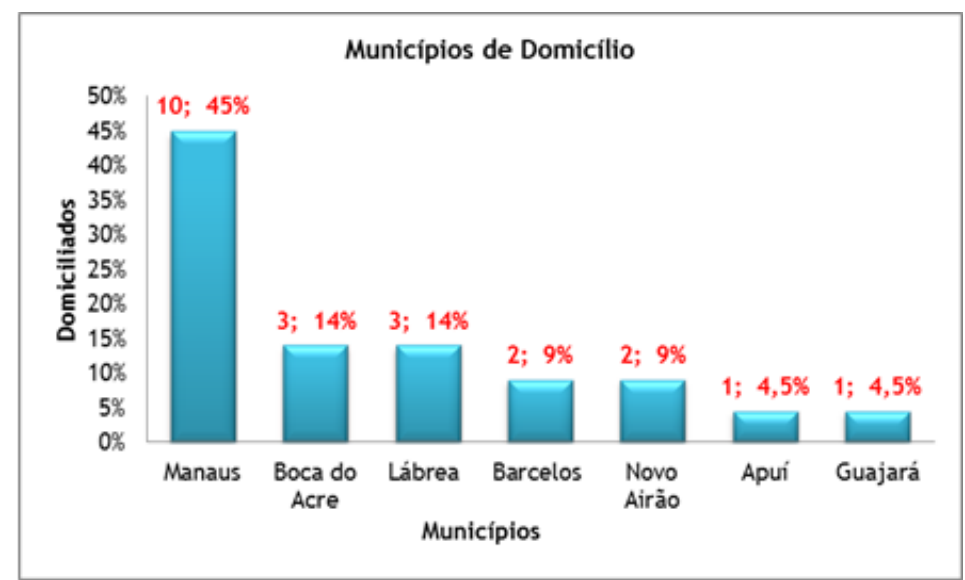

Figura 5: Número total e porcentagem de infratores por município de domicílio. 
Mais de $50 \%$ dos infratores do estado do Amazonas residiam no mesmo município em que cometeram o delito (Figura 6).

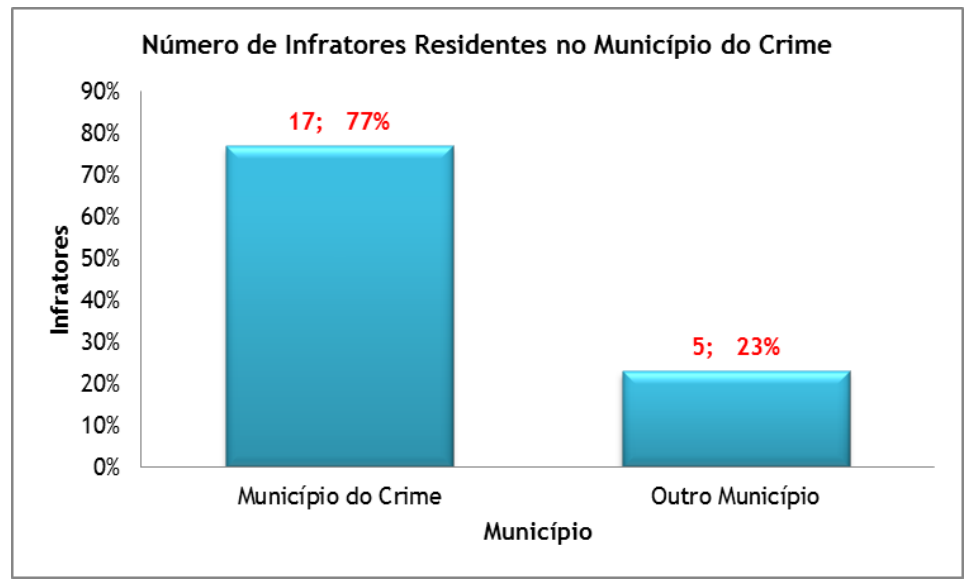

Figura 6: Número total e porcentagem de infratores que residem no município do crime.

Os infratores residentes no Acre foram responsáveis por $44,4 \%$ dos crimes cometidos em Lábrea e 66,6\% dos crimes cometidos em Boca do Acre.

Dos 28 casos analisados, 7,1\% dos infratores respondiam a outros processos por crime ambiental em fóruns de outros estados brasileiros, como São Paulo e Acre, sendo que estes também eram domiciliados no Acre (Figura 7).

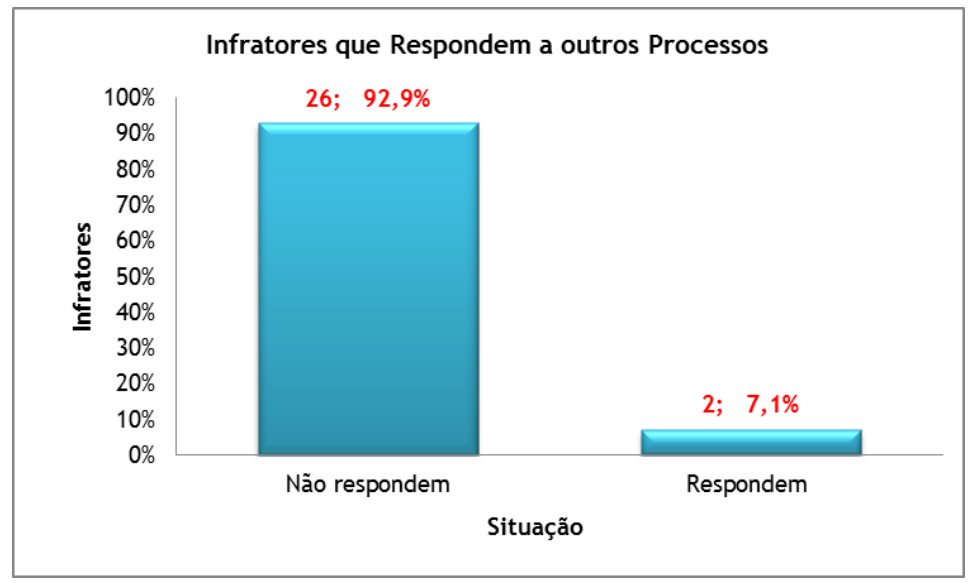

Figura 7: Número total e porcentagem de infratores que respondem a outros processos. 


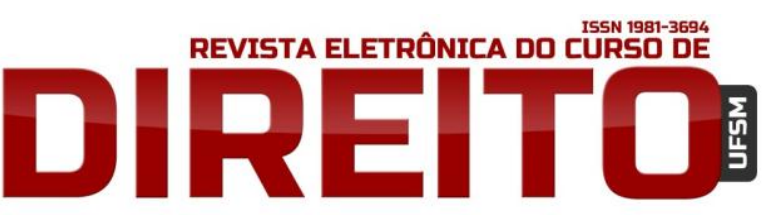

DIAGNÓSTICO DOS CRIMES CONTRA A FLORA A PARTIR DAS AÇÕES IMPETRADAS PELO MINISTÉRIO PÚBLICO FEDERAL

As estradas vindas principalmente dos estados do Acre e Rondônia são os principais vetores dos crimes contra a flora nos municípios de Lábrea e Boca do Acre. São por elas que chegam agricultores, pecuaristas e madeireiros, vindos de outras regiões do Brasil e se assentam nestes municípios onde desenvolvem suas atividades ${ }^{6}$.

Com base nos resultados, acredita-se que são estes trabalhadores rurais, vindos principalmente do estado vizinho, os principais responsáveis pelos danos causados à flora, pois segundo Mariano Colini Cenamo ${ }^{7}$, a agricultura desenvolvida pela população destes municípios é praticada em pequena escala, para sua subsistência ou comercialização no mercado local.

\subsection{Tipologia dos crimes contra a flora.}

De acordo com os dispositivos legais da Lei de Crimes Ambientais, nos processos analisados, o delito contra a flora cometido com maior frequência no Amazonas foi o desmatamento ilegal com $78,6 \%$ dos casos, seguido da exploração predatória de madeira, com $14,3 \%$, e queimada com, $7,1 \%$ (Figura 8 ).

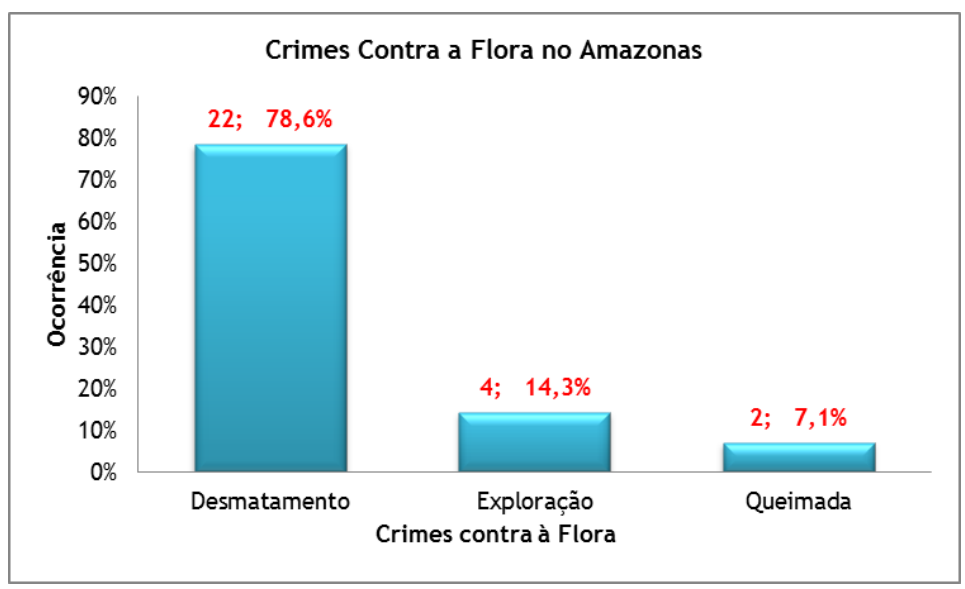

Figura 8: Número total e porcentagem dos tipos de crime contra a flora ocorridos no Amazonas.

\footnotetext{
${ }^{6}$ CENAMO, Mariano Colini; CARRERO, Gabriel Cardoso; SOARES, Pedro Gandolfo. Redução de Emissões do Desmatamento e Degradação Florestal (REDD+): Estudo de Oportunidades para a Região Sul do Amazonas. IDESAM. Manaus. 56 p. 2011.

${ }^{7}$ CENAMO, Mariano Colini; CARRERO, Gabriel Cardoso; SOARES, Pedro Gandolfo. Redução de Emissões do Desmatamento e Degradação Florestal (REDD+): Estudo de Oportunidades para a Região Sul do Amazonas. IDESAM. Manaus. 56 p. 2011.
} 
O desmatamento na Amazônia deve-se principalmente à expansão agropecuária, que converte grandes extensões de terras para o seu desenvolvimento e em geral é acompanhada por um extrativismo predatório. Mas existem outros fatores que favorecem o desmatamento ilegal na Amazônia, tais como a grilagem de terras públicas, a exploração madeireira e a abertura de estradas $^{8}$.

A exploração ilegal decorre do corte de espécies florestais por madeireiras que visam o abastecimento do mercado externo, sem considerar a capacidade de regeneração da floresta. Acredita-se que boa parte da exploração de madeira na Amazônia é feita sem manejo madeireiro e com isso madeiras de valor econômico são perdidas na exploração irracional ${ }^{9}$.

Já as queimadas na Amazônia tem grande importância na limpeza de áreas para a agricultura de subsistência da região. Trata-se de uma prática cultural antiga, onde a queima é adotada para limpeza de terrenos. Porém o aumento nos índices está associado à expansão agrícola e à exploração madeireira que aumentam consideravelmente a vulnerabilidade da floresta ao fogo ${ }^{10}$.

Os delitos observados, durante a análise dos processos enquadram-se nos arts. $38,41,45$ e 50 da Lei 9.605/98, os quais consideram crime ambiental contra a flora:

"Destruir ou danificar floresta considerada de preservação permanente, mesmo que em formação, ou utilizá-la com infringência das normas de proteção (Art. 38)"; "Provocar incêndio em mata ou floresta (Art. 41)"; "Cortar ou transformar em carvão madeira de lei, assim classificada por ato do Poder público, para fins industriais, energéticos ou para qualquer outra exploração, econômica ou não, em desacordo com as determinações legais (Art. 45)"; e "Destruir ou danificar florestas nativas ou plantadas ou vegetação fixadora de dunas, protetora de mangues, objeto de especial preservação (Art. 50)"11.

Tais crimes provocam danos diretos à flora, com consequências muitas vezes irreversíveis, como o desaparecimento de espécies florísticas e faunísticas, perda da qualidade de rios e erosão do solo.

\footnotetext{
${ }^{8}$ CUNHA, Sandra Baptista da Cunha; GUERRA, Antonio José Teixeira. Avaliação e Perícia Ambiental. Bertrand Brasil, Rio de Janeiro. 286 p. 2009.

9 CUNHA, Sandra Baptista da Cunha; GUERRA, Antonio José Teixeira. Avaliação e Perícia Ambiental. Bertrand Brasil, Rio de Janeiro. 286 p. 2009.

10 SOUZA, Nilton José. Influência das Queimadas da Amazônia sobre o Efeito Estufa. Universidade Federal do Paraná - UFPR. 6 p. 2008.

${ }^{11}$ BRASIL. Lei 9.605 de 12 de fevereiro de 1998. Dispõe sobre sanções penais e administrativas derivadas de conduta e atividades lesivas ao meio ambiente e dá outras providências. Meio Ambiente legal - Manaus: VEMAQA, 2008.
} 
Durante o estudo, foi observado que os crimes foram identificados em ações de fiscalização e monitoramento do IBAMA, sendo que em algumas operações contou-se com a presença de agentes da Polícia Civil e da Polícia Federal.

$\mathrm{Na}$ totalidade dos casos não houve apreensão de bens utilizados ou gerados na prática do crime e o IBAMA foi o órgão fiscalizador responsável pela comunicação dos delitos ao Ministério Público Federal.

\subsection{Zoneamento das áreas de ocorrência dos crimes contra a flora.}

A maior incidência de crimes contra a flora ocorreu nos municípios de Lábrea, Manaus, Boca do Acre e Novo Airão (Figura 9).

Com exceção de Novo Airão que apresentou crimes de desmatamento e exploração ilegal, todos os crimes praticados nos municípios com maior incidência de delitos, corresponderam a desmatamento.

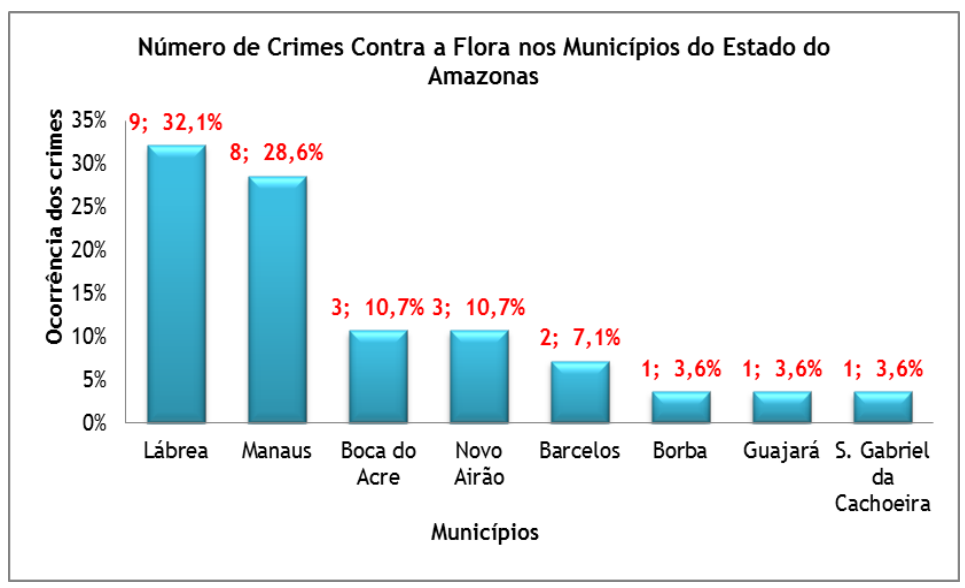

Figura 9: Número total e porcentagem de crimes contra a flora ocorridos por município no Amazonas.

O maior índice de desmatamento em Lábrea vislumbra-se pelo fato de que este município está localizado em região de maior atividade predatória de madeira e expansão agropecuária, atividades que exigem grandes extensões de terras. 
A pouca presença do Estado e a carência de regularização fundiária, com milhares de produtores em posse de propriedades não tituladas, favorece um cenário de destruição da floresta para exploração de recursos naturais e a implantação de pastagens ${ }^{12}$.

Quanto ao município de Boca do Acre entende-se que ocorre da mesma forma que em Lábrea, pois o município possui um cenário produtivo e econômico dominado pela pecuária, o que o torna o maior produtor de gado de corte do Estado do Amazonas ${ }^{13}$.

O destaque de Manaus quanto ao número de crimes, deve-se ao número de infratores identificados na área do delito. Todos são trabalhadores rurais, residentes em assentamentos localizados nas proximidades, que desmataram a área para implantação de cultivo agrícola.

Em geral, na criação dos assentamentos não são consideradas as características da paisagem natural e isso favorece o desmatamento de áreas de relevante interesse ecológico.

Quanto à posição de Novo Airão deve-se ao fato de existir no município madeireiras que invadem as terras da União e exploram ilegalmente madeiras de considerado valor econômico para comercialização.

$\mathrm{Na}$ totalidade dos casos analisados foi verificado que os delitos contra a flora no Amazonas, no período estudado, foram cometidos em áreas de responsabilidade da administração federal (IBAMA e INCRA), Unidades de Conservação Federais, faixa de fronteira área de segurança nacional e em terras indígenas (Figura 10), sendo estas áreas de competência dos juízes federais para processar e julgar os crimes, de acordo com o art. 109, IV, da Constituição Federal que dispões: “Aos juízes federais compete processar e julgar: os crimes políticos e as infrações penais praticadas em detrimento de bens, serviços ou interesses da União ou de suas entidades autárquicas ou empresas públicas, excluídas as contravenções e ressalvada a competência da Justiça Militar e da Justiça Eleitoral” ${ }^{14}$.

\footnotetext{
${ }^{12}$ CENAMO, Mariano Colini; CARRERO, Gabriel Cardoso; SOARES, Pedro Gandolfo. Redução de Emissões do Desmatamento e Degradação Florestal (REDD+): Estudo de Oportunidades para a Região Sul do Amazonas. IDESAM. Manaus. 56 p. 2011.

${ }^{13}$ CENAMO, Mariano Colini; CARRERO, Gabriel Cardoso; SOARES, Pedro Gandolfo. Redução de Emissões do Desmatamento e Degradação Florestal (REDD+): Estudo de Oportunidades para a Região Sul do Amazonas. IDESAM. Manaus. 56 p. 2011.

${ }^{14}$ BRASIL. Constituição Federal. Brasília: Senado Federal, 1988.
} 


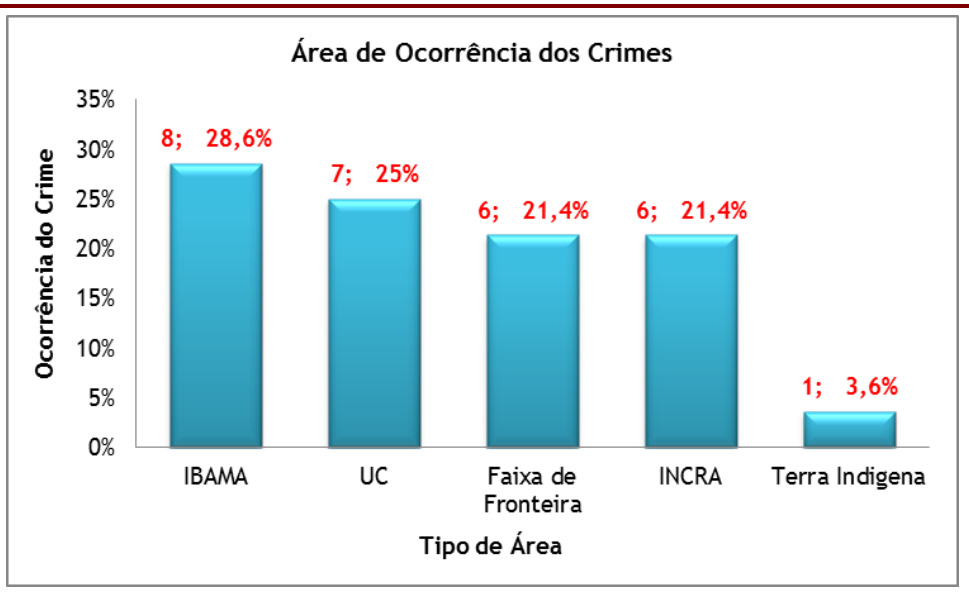

Figura 10: Número total e porcentagem de crimes contra a flora por tipo de área de ocorrência.

Em Lábrea e Boca do Acre os crimes foram praticados em áreas de assentamentos de responsabilidade do INCRA e na faixa de fronteira com a Bolívia. "Nestas áreas há problemas com ordenamento fundiário e dificuldade de acesso dos órgãos fiscalizadores"15. Então se acredita que estes fatores possam ter contribuído para ocorrência destes crimes, possibilitando que grileiros subtraiam terras da União com o objetivo de aumentar a área de seus imóveis para a prática da pecuária e agricultura.

Nessa região os agentes privados são grandes empresários que vivem em Porto Velho ou Rio Branco que tem fazendas consolidadas com grandes rebanhos, em terras griladas ou tituladas pelo INCRA ${ }^{16}$.

Em Lábrea, além destas áreas os infratores também praticaram crimes em Unidade de Conservação (Floresta Nacional do Iquiri), no qual adentraram a área para desmatamento e provavelmente comercializaram ilegalmente a madeira extraída da FLONA.

Percebe-se que as áreas são carentes de fiscalização, o que facilita a ação dos infratores, para que transgridam as leis ambientais sem medo de serem punidos.

No município de Manaus a prática de crime ocorreu em sua totalidade na área do Centro de Criação de Animais Nativos - CECAN, Ramal do Pau-rosa, caracterizada como uma área de

\footnotetext{
${ }^{15}$ CENAMO, Mariano Colini; CARRERO, Gabriel Cardoso; SOARES, Pedro Gandolfo. Redução de Emissões do Desmatamento e Degradação Florestal (REDD+): Estudo de Oportunidades para a Região Sul do Amazonas. IDESAM. Manaus. 56 p. 2011.

${ }^{16}$ CENAMO, Mariano Colini; CARRERO, Gabriel Cardoso; SOARES, Pedro Gandolfo. Redução de Emissões do Desmatamento e Degradação Florestal (REDD+): Estudo de Oportunidades para a Região Sul do Amazonas. IDESAM. Manaus. 56 p. 2011.
} 
relevante interesse ecológico. A competência da União fica em tese caracterizada por se tratar de uma área de responsabilidade da administração do IBAMA, que é de autarquia federal.

Os crimes denunciados nesta área resultaram de uma operação do IBAMA, que identificou várias pessoas envolvidas na prática de desmatamento.

Em Novo Airão os delitos foram praticados no Parque Nacional de Anavilhanas, onde madeireiros invadiram a área, desrespeitando sua fiscalização e desmataram para retirada de madeira.

No município de São Gabriel da Cachoeira, os crimes contra a flora ocorreram em Terras Indígenas, onde infratores exploravam ilegalmente madeira para comercialização.

Com o objetivo de proteger e conservar a biodiversidade observa-se que várias Unidades de Conservação têm sido criadas, mas para que estas áreas, assim como as Terras indígenas, sejam efetivas na conservação da biodiversidade, algumas medidas devem ser tomadas, tais como, a demarcação e sinalização das áreas e a realização de oficinas e atividades educacionais com a população do entorno, a fim de evitar a invasão das áreas por infratores.

\subsection{Condições dos processos na justiça federal.}

Dos 41 processos judiciais que tratavam de crimes diretos contra flora, impetrados pelo Ministério Público Federal no período de 01 de Janeiro de 2009 a 31 de Dezembro de 2010, 28 processos estavam tramitando, 10 já estavam arquivados e 3 haviam sido encaminhados para a Justiça Estadual por incompetência.

Os processos na Justiça Federal encontravam-se em várias fases de tramitação. Destes, $35,7 \%$ estavam aguardando citação do acusado, ou seja, fase em que o réu toma conhecimento que the movem uma ação penal e é chamado a comparecer em audiência judicial, 28,6\% aguardavam audiência, 21,4\% estavam cumprindo acordo para evitar o processo ou suspensão da pena e $14,3 \%$ haviam cumprido acordo (Figura 11). 


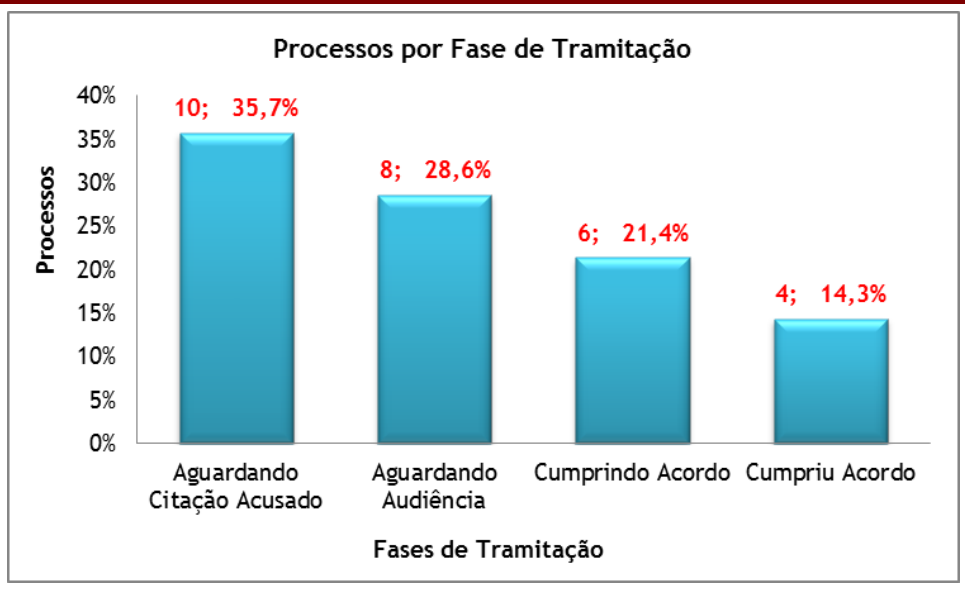

Figura 11: Número total e porcentagem de processos por fase de tramitação.

O grande número de processos na fase de citação ocorre devido ao fato de que Juízes Federais tem que expedir Carta Precatória para solicitar que juízes estaduais da comarca onde o infrator reside, promovam a citação do réu quanto ao processo.

Conforme informações contidas nos processos, observou-se que em vários casos o infrator não é localizado, pelo fato de não ter fornecido o endereço corretamente, ou por ter mudado de endereço. 0 que dificulta a sua tramitação.

Os acordos que ainda estão sendo cumpridos foram aceitos em audiência de Transação Penal e Composição Civil dos Danos ou de Suspensão do Processo. Na maioria dos casos o Ministério Público Federal propôs como Transação Penal a prestação de serviços em órgão ambiental com sede no município onde reside o infrator, e na falta deste em outra instituição de interesse social. Já o IBAMA, propôs como Composição Civil dos Danos ou Suspensão do processo, a participação em uma oficina de Educação Ambiental para apenados realizada pelo Núcleo de Educação Ambiental do IBAMA e fornecimento de combustível para o órgão fiscalizador (IBAMA) como auxílio em suas ações ambientais.

Observou-se que em alguns casos os infratores que aceitaram participar de oficina de Educação Ambiental para apenados, ainda não cumpriram o acordo, porque havia uma demora no fornecimento da programação por parte do IBAMA.

Nos casos em que os acordos haviam sido cumpridos, em Sentença o juiz declarou extinta a punibilidade e expediu Carta Precatória para comunicação das partes e posterior arquivamento. 


\subsection{Relação dos Crimes Contra a Flora e as Perícias Realizadas.}

Dos 28 processos analisados observou-se que em somente $2(7 \%)$ casos foram realizadas perícias necessárias para elucidação dos fatos.

De acordo com informações existentes nos processos, estas perícias foram realizadas por peritos criminais federais, vinculados a Policia Federal.

No primeiro processo, que é referente ao crime de desmatamento no Município de Boca do Acre, em área de assentamento do INCRA, o perito realizou vistoria no local discriminado e comprovou que houve crime contra a flora, pois constatou que a quase totalidade da área havia sido desmatada e estava ocupada com pastagem.

No segundo processo, o delito ocorreu no município de Lábrea, onde foram desmatados 485,23 hectares de floresta primária. Neste caso, o perito não conseguiu acesso ao local do crime ambiental, pois necessitava de logística, da qual o órgão não possuía, para comprovação do dano in loco. Então para atestar a veracidade dos fatos o perito utilizou imagens de satélite, observando que a área havia sido desmatada, conforme informado pelo órgão ambiental fiscalizador.

Em ambos os casos os infratores eram residentes de Rio Branco no Acre e de acordo com informações contidas nos processos eram os principais responsáveis pelas infrações nos municípios de fronteira e estavam envolvidos com o agronegócio. “Estas pessoas se aproveitam da pouca fiscalização das áreas da União para expansão de suas atividades"17.

\subsection{Hipóteses indicadoras de crimes contra a flora, no estado do Amazonas.}

De acordo com os resultados obtidos e informações da bibliografia consultada, as estradas que interligam os munícipios do sul do Amazonas aos Estados Limítrofes facilitam a entrada de pessoas com o objetivo exclusivo de praticar crimes ambientais no Amazonas. Segundo o levantamento realizado, o desmatamento no Estado é ocasionado principalmente pelas práticas de agricultura, pecuária e exploração madeireira. Em sua maioria, pessoas diretamente envolvidas com o agronegócio invadem áreas da União, em seu benefício econômico.

${ }^{17}$ CENAMO, Mariano Colini; CARRERO, Gabriel Cardoso; SOARES, Pedro Gandolfo. Redução de Emissões do Desmatamento e Degradação Florestal (REDD+): Estudo de Oportunidades para a Região Sul do Amazonas. IDESAM. Manaus. 56 p. 2011. 
Nos municípios de Lábrea e Boca do Acre, o índice elevado de desmatamento ocorre especificamente pela localização, estando os mesmos insertos em região de maior atividade predatória de madeira e expansão agropecuária.

Em Manaus, o desmatamento é decorrente principalmente da implantação de cultivo agrícola e da expansão Urbana. Bem como, de maneira geral, a suscetibilidade das Áreas da União, frente à ação de invasores infratores, ocorre devido a sua pouca fiscalização, grande extensão e problemas fundiários. Potencializado pelo fato, dos órgãos ambientais apresentarem melhor estrutura para operações em municípios mais próximos à capital do estado.

\section{CONCLUSÃO}

Apesar das ações criminais por crimes contra a flora objeto dos processos analisados, terem sido impetrados nos anos 2009 e 2010, a maioria dos atos criminosos ocorreu no ano de 2003. Ano em que houve o maior índice de desmatamento no estado do Amazonas. Acredita-se que esta demora entre a data do crime e a data do oferecimento de denúncia deve-se principalmente ao tempo do trâmite do processo administrativo nos órgãos fiscalizadores e sua comunicação ao Ministério Público Federal.

Entre os processos analisados, observou-se que infratores vindos de outro estado, invadem áreas da União e cometem crimes em seu benefício econômico, desrespeitando as leis, os limites das áreas e até mesmo moradores dos municípios onde cometem o delito, sem medo de serem punidos, estes são responsáveis pela maioria dos crimes contra a flora nos municípios do sul do Amazonas. A maioria dos infratores que residem no Amazonas é domiciliada em Manaus, mas isso não significa que os crimes sejam cometidos no município onde residem, pois há registros de desmatamento e exploração madeireira em outros municípios do estado, provocados por estes infratores.

O número de infratores que respondem a outros processos é pequeno quando comparado com o número de casos analisados, mas acredita-se que estes sejam os mais perigosos, pois são pessoas originárias do Acre, estado com histórico de desmatamento e exploração irracional de madeira, que se assentam nestes municípios em busca de novas fontes de madeira para explorarem ou para expansão de suas áreas agrícolas.

Os delitos contra a flora cometidos no Amazonas com maior frequência foram o desmatamento, a exploração predatória de madeira e as queimadas. Acredita-se que estes 
crimes estejam relacionados com as atividades ilegais de madeira e agropecuária, sendo que grande parte destas ocorrências foram registradas nos municípios do sul do Amazonas, área bastante problemática quanto à questão ambiental, já que a pouca fiscalização na região, a falta de demarcação de algumas áreas de floresta nativa e o grande volume de madeira de alto valor comercial são atrativos para atos delituosos.

Em Manaus o desmatamento foi o crime que ocorreu na totalidade dos casos. O seu destaque entre os municípios de maior ocorrência de crimes, deve-se a quantidade de infratores que foram identificados em uma operação de monitoramento do IBAMA e a facilidade de acesso ao local do crime, pois o fato de ter ocorrido em uma área de responsabilidade do IBAMA propicia melhores condições para o trabalho da equipe de fiscalização que conhece os limites da área. Além de o órgão possuir melhor estrutura para realizar ações na capital, quando comparadas com as operações no interior que geralmente são onerosas e demandam maior estrutura e maior número de profissionais para a realização.

No estudo observou-se que as áreas de responsabilidade da administração federal, Unidades de Conservação, Faixa de Fronteira e Terras Indígenas necessitam de melhor gestão, maior fiscalização e monitoramento, além de ter seus limites bem demarcados para evitar invasão de infratores.

Dos processos judiciais que tratavam de crimes diretos contra a flora, impetrados pelo Ministério Público Federal, no período estudado, 28 estavam tramitando, 10 estavam arquivados e 3 haviam sido encaminhados para a Justiça Estadual.

O maior índice de processos aguardando citação do acusado facilita a fuga dos infratores, além de aumentar a impunidade destes, que continuam a cometer crimes contra a flora, principalmente em áreas de floresta nativa.

Quanto aos acordos sugeridos nas audiências de transação penal e composição dos danos, observa-se o descaso do órgão ambiental fiscalizador quanto à demora no fornecimento da programação das atividades para apenados, além de observar que estes acordos são insignificantes quando comparados com os efeitos danosos sobre as florestas, sendo necessária uma avaliação destas propostas para que haja maior punição. 


\section{REFERÊNCIAS}

BRASIL. Constituição Federal. Brasília: Senado Federal, 1988.

BRITO, Brenda; BARRETO, Paulo. Aplicação da Lei de Crimes Ambientais pela Justiça Federal no Setor Florestal do Pará. Revista de Direito Ambiental. São Paulo. n. 37, p.218-243, 2005 a.

CENAMO, Mariano Colini; CARRERO, Gabriel Cardoso; SOARES, Pedro Gandolfo. Redução de Emissões do Desmatamento e Degradação Florestal (REDD+): Estudo de Oportunidades para a Região Sul do Amazonas. IDESAM. Manaus. 56 p. 2011.

CUNHA, Dacicleide Souza. Análise Econômica-Jurídica da Efetividade da Lei de Crimes Ambientais nos Delitos Contra Flora no Amapá. Universidade Federal do Amapá, Macapá, 2009.

CUNHA, Sandra Baptista da Cunha; GUERRA, Antonio José Teixeira. Avaliação e Perícia Ambiental. Bertrand Brasil, Rio de Janeiro. 286 p. 2009.

. Lei 9.605 de 12 de fevereiro de 1998. Dispõe sobre sanções penais e administrativas derivadas de conduta e atividades lesivas ao meio ambiente e dá outras providências. Meio Ambiente legal - Manaus: VEMAQA, 2008.

NETO, Nicolau Dino de Castro e Costa; FILHO, Ney de Barros Bello; COSTA, Flávio Dino de Castro e. Crimes e Infrações Administrativas Ambientais: comentários à Lei no 9.605/98, 2a edição rev. e atual. Brasília: Brasília Jurídica, 2001 a.

PLANO DE AÇÃO PARA PREVENÇÃO E CONTROLE DO DESMATAMENTO NA AMAZÔNIA LEGAL. Manaus, 2004. Disponível em: <http: / /www. planalto.gov.br/casacivil/desmat.pdf>. Acesso em: 7 jun. 2011.

SDS. Secretaria de Estado do Meio Ambiente e Desenvolvimento Sustentável. In: Ações de governo e mudanças climáticas. Manaus, 2009. Disponível em: <http://www.senado.gov.br/sf/comissoes/CMMC/AP/AP20091119_CECLIMA.pdf>. Acesso em: 20 maio 2011.

SDS. Secretaria de Estado do Meio Ambiente e Desenvolvimento Sustentável. In: Plano Estadual de Prevenção e Combate ao Desmatamento no Amazonas. Manaus, 2008. Disponível em:

<http://www.fundoamazonia.gov.br/FundoAmazonia/export/sites/default/site_pt/Galerias/Arq uivos/Publicacoes/Plano_Estadual_do_Amazonas.pdf>. Acesso em: 12 mar. 2011.

SOUZA, Nilton José. Influência das Queimadas da Amazônia sobre o Efeito Estufa. Universidade Federal do Paraná - UFPR. 6 p. 2008.

Recebido em: 11 mar. 2013

Revisões requeridas em: 04 jul. 2013

Aprovado em: 09 jul. 2013 